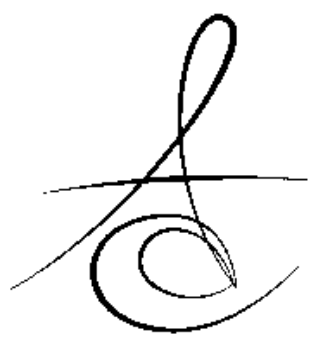

PORSELEN LAMİNATE VENEERLER

PORCELAIN LAMINATE VENEERS

Dt. Hamit Fatih ERKÜN*

Öğr. Gör. Dr. Merve BANKOĞLU GÜNGÖR*

Prof. Dr. Handan YILMAZ*

Makale Kodu/Article code: 2566

Makale Gönderilme tarihi: 24.01.2016

Kabul Tarihi; 08.06.2016

ÖZET

Hastaların kaybolan estetik görüntülerinin yeniden kazandırılmasında dental estetik önemli bir yer tutmaktadır. Bu amaçla günden güne bir çok gereç ve yöntem üretilmektedir. Mevcut diş yapısının mümkün olduğunca korunduğu estetik restorasyonlar diş hekimleri tarafından daha çok tercih edilmektedir. Bu restorasyonlardan biri olan porselen laminate veneer restorasyonlar, diş anomalilerini düzeltebilmek ve diş renklenmelerini maskeleyebilmek amacıyla sıklıkla kullanılmaktadır. Bu restorasyonların uzun süre ağızda başarılı bir şekilde kullanılmasında; laminate veneer yapımında kullanılan madde çeşidi, preparasyon şekli, simantasyon prosedürü ve hasta alışkanlıkları önemlidir. Bu nedenle uygun endikasyonun konulması ve klinikte ve laboratuarda hassas çalışma laminate veneerlerde anahtar rol oynamaktadır. Bu literatür derlemesinin amacl; porselen laminate veneerler konusunda geniş ve güncel çalışmaları sunmak ve laminate veneerlerde madde çeşidi, preparasyon, simantasyon ve başarı oranı hakkında bilgi vermektir.

Anahtar Kelimeler: Dental estetik; dental laminat; seramikler

\section{PORSELEN LAMİNATE VENEERLER}

Porselen laminate veneerler, anterior ön bölge dişlerinde boyut, renk veya pozisyon değişikliğine gerek duyan hastalarda uygulanan restorasyonlardır. ${ }^{1}$ Geliştirilen adeziv teknolojilerle daha fazla diş yapısını koruyarak, yüksek mekanik özelliklere sahip ve aynı zamanda estetik porselen laminate veneerlerin yapımı mümkün olmuştur. ${ }^{2}$ Laminate veneerler direkt ve indirekt olarak kompozit veya porselen ile şekillendirilmektedir. ${ }^{3}$ Kompozit laminate veneerler renklenmiş

\section{ABSTRACT}

Dental esthetic is an important topic to re-establish patients' lost esthetic appearance. For this aim, new materials and methods have been improved day by day. Esthetic restorations which prevent much more residual tooth structure have been preferred by the dentists. Porcelain laminate veneers which are one of these restorations are used to correct tooth abnormalities and to mask tooth discolorations. Material type of laminate veneer restoration, preparation, cementation, and patient related habits are important for the long-term successful using of these restorations in the oral cavity. Thus, appropriate indication and presicion laboratory and clinical work are crucial factors for laminate veneers. The aim of this literature review is to summarize comprehensive and current studies on this field and to give information about material type, preparation, cementation, and success rate of laminate veneers.

Key words: Ceramics; dental esthetics; dental laminate

dişlerde rengi maskeleyebilmek için ve hasar görmüş anterior dişlerde minimal invaziv yöntemlerle kullanılmaktadır. ${ }^{4,5}$ Ancak bu materyaller renk değişimine ve aşınmaya karşı porselen veneerler kadar dayanıklı değildir. Sık sık tamir edilmeleri, yeniden yerleştirilmeleri veya yenilenmeleri gerekmektedir., 4 Günümüzde porselen laminate veneer restorasyonlar marjinal bölgedeki kırılma dayanımı, uzun dönem renk stabilitesi ve aşınmaya karşı direncinden dolayı sıklıkla kullanılmaktadır. ${ }^{3-6}$

\footnotetext{
* Gazi Üniversitesi, Diş Hekimliği Fakültesi, Protetik Diş Tedavisi Anabilim Dalı
} 
Veneer kron preparasyonu, normal diş yapısının $\% 63$ ile \%73'ünü uzaklaştırılabilmekte, ${ }^{7,8}$ pulpal irritasyona ve geri dönüşümü olmayan pulpitise sebep olabilmektedir. ${ }^{9}$ Laminate veneer preparasyonları ise daha konservatiftir ve estetik, renk stabilitesi ve mine dokusuna adezyon diğer avantajları arasındadır. ${ }^{7,9-12}$

Porselen laminate veneerlerin uzun dönem başarısını etkileyen etkenler diş yüzeyinin yapısı, preparasyon derinliği, porselen tipi ve kalınlığı, rezin simanın ve dental adezivin tipi, diş morfolojisi, fonksiyonel ve parafonksiyonel çene hareketleridir. ${ }^{10,11} \mathrm{Bu}$ restorasyonların en önemli başarısızılık nedenleri ise kırılma, mikrosızıntı ve diş yüzeyinden ayrılmalardır. ${ }^{13,14}$

Porselen laminate veneerler piyasaya ilk çıktıkları dönemlerde, diş preparasyonu yapılmadan ya da çok az miktarda preparasyon yapılarak uygulanmaktaydı. ${ }^{14,15}$ Ancak günümüzde uzun dönem başarı elde edilmesi amacıyla diş preparasyonu yapılması önerilmekte ${ }^{15}$ ve daha estetik restorasyonların yapımı, kırılma direncinin arttırıması ve yumuşak doku sağıı̆ının idame ettirilmesi amaçlanmaktadır. ${ }^{15-17}$ Porselen laminate veneerler, tetrasiklin ve florosiz renklenmelerinin maskelenmesi gereken hastalarda, hipokalsifikasyon ve amelogenesis imperfekta hastalarında, insizal bölge kırıklarında, malforme dişlerde ve basit diastema vakalarında endikedir. ${ }^{17-21}$ Düşük interoklüzal mesafelerde, bruksizm ve parafonksiyonel aktivite varlğında, şiddetli malpozisyon, derin overbiteve yumuşak doku hastalıklarına sahip vakalarda ise kontrendikedir. ${ }^{2}$ materyaller

Porselen laminate veneer yapımında kullanılan

Günümüzde laminate veneerler için kullanılan materyaller, toz-likit firınlama yöntemi ile üretilen feldspatik seramikler, cam seramikler, oksit seramikler ve CAD/CAM yöntemi ile hazırlanan seramiklerdir. 22,23 Laminate veneer yapımında kullanılan materyaller ve üretim yöntemleri Tablo 1'de özetlendi.

Tablo 1. Laminate veneer yapımında kullanılan materyaller

\begin{tabular}{|l|l|}
\hline Feldspatik seramikler & $\begin{array}{l}\text { Toz/likit firılama } \\
\text { CAD/CAM }\end{array}$ \\
\hline $\begin{array}{l}\text { Cam seramikler } \\
\text { (Lösit ile güçlendirilen cam seramikler) } \\
\text { (Lityum disilikat içerikli seramikler) }\end{array}$ & $\begin{array}{l}\text { Isı ve basınç ile } \\
\text { presleme } \\
\text { CAD/CAM }\end{array}$ \\
\hline Oksit seramikler & CAD/CAM \\
\hline Hibrit seramikler & CAD/CAM \\
\hline
\end{tabular}

\section{- Feldspatik seramikler}

Feldspatik seramik yüksek translüsesiye sahip estetik bir materyal olmasına rağmen materyalin mekanik özellikleri düşüktür. Mekanik streslerde bu materyaller altyapısı bulunmadan yeteri kadar direnç gösteremezler. ${ }^{2}$ Feldspatik seramiklerin, mineye olan simantasyonu dentine göre daha iyidir. Sağlıkı dişlerde mine sınırları içinde preparasyon yapıldığı zaman yüksek estetik gereksinimleri karşılamak amacıyla feldspatik seramikler kullanilabilir. Feldspatik seramiklerde simantasyon yapılacak diş yüzey alanının en az $\% 50^{\prime}$ sinin mine olması, simantasyon yapılacak kenarların ise en az $\% 70^{\prime}$ inin mine olması önerilmektedir. ${ }^{24,25}$ Genel olarak desteklenmemiş geniş seramik alanlarında, derin overbite, esnek altyapıya (dentin, kompozit restorasyon) simantasyonunda, bruksizm varlığında, restorasyon distale uzandığında yüksek gerilme ve makaslama kuvvetleri oluşur. ${ }^{26}$ Bu yüksek riskli durumlarda cam seramikler tercih edilebilir. ${ }^{2}$ Feldspatik seramikler travmatik parafonksiyonel kuvvetler mevcudiyetinde, başa baş kapanış durumunda ve fonksiyon sırasında yüksek stres durumunda kontrendikedir. ${ }^{27}$

Feldspatik seramikler geleneksel toz-likit fırınlama yöntemleri ile elde edilir. Bunun yanında son zamanlarda feldspatik seramikler CAD/CAM yöntemleri ile şekillendirilmektedir. Prefabrike feldspatik bloklar direkt olarak dijital aşındırma sistemleri ile şekillendirilir ve tek seansta hazırlanarak tamamlanırlar. Hazirlanan restorasyon simantasyondan önce renklendirilir ve glazelenir veya simantasyondan sonra mekanik olarak parlatma setiyle polisajlanır. ${ }^{28}$ Feldspatik seramiklerin ilk 5 ylda \%96, 10 yllda \%93, 12 yılda $\% 91$ başarı oranı gösterdiği bildirilmiştir. ${ }^{29}$

\section{- Cam seramikler}

Cam seramikler, yüksek kırıma dayanımı, yüksek ısısal şok dayanımı ve aşınmaya direnç gösterirler. ${ }^{30,31}$ Cam matriks mikron boyutlarda lösit ve lityum disilikat kristalleri ile infiltre edilerek, yüksek dolduruculu cam matriks elde edilir. ${ }^{32}$ Lösit ve lityum disilikat veneerler kayıp mum ve ısı ile presleme tekniklerinin kombinasyonları ile üretilebilmesinin yanı sıra son zamanlarda CAD/CAM yöntemi ile de üretilebilmektedir. ${ }^{33}$

Lösit içerikli cam seramiklerde lösitin asitlenebilme özelliğinden dolayı bonding işlemi diğer cam seramiklere göre daha başarılı sonuç verir. ${ }^{34}$ Lityum disilikat ile güçlendirilmiş cam seramikler \%70 kristal fazından dolayı yüksek esneklik direnci gösterir. 
Bununla birlikte yeterli translüsensi özelliğinin olması sayesinde monolitik yapımda kullanılabildiği gibi veneerleme de yapılabilir. ${ }^{30,34}$ Cam seramikler fonksiyonel kuvvetlerin fazla olduğu durumlarda tercih edilmektedir. Materyal kalınlığı 0,8 mm'den fazla olmalıdır. Marjinal kenarlarda kademeli olarak 0,3 mm'ye düşebilir. ${ }^{24,25} 0,8 \mathrm{~mm}$ 'lik preparasyon derinliği ile restorasyonun hem mekanik özelliklerinin yüksek olması hem de estetik gereksinimlerinin karşılanabilmesi sağlanmaktadır. Simantasyon yapılacak bölgenin en az \%50 oranında, marjinal kenarlarda ise minimum \%30 oranında mine tabakası bulunması önerilmektedir. $^{2}$

\section{- Oksit seramikler}

Aluminyum oksit ve zirkonyum oksit seramikler yüksek fiziksel özelliklere sahip olmasına rağmen, opasitelerinden dolayı genellikle altyapı materyali olarak kullanılırlar. ${ }^{18}$ Zirkonya, alumina seramiklere göre yüksek esneklik dayanımı ve kırılma tokluğu gösterir. ${ }^{27}$ Zirkonya laminate veneerler, CAD/CAM sistemlerinde 0,2-0,3 mm kalınlığında hazırlanabilirler. $\mathrm{Bu}$ materyaller geniş diastema varlığında veya lingual yüzeyine kadar travma veya çürük nedeniyle kırılmış dişlerde kullanılabilirler. Ayrıca diş kaybının daha fazla olduğu durumlarda 2 mm'den fazla kalınlık gerektirdiği durumlarda veneer materyaline kor olarak kullanılabilir. $^{27}$ Zirkonyanın opak özelliği yaşa bağlı renklenmiş veya tetrasiklin renklenmeleri bulunan vakalarda minimal diş preparasyonu ile rengin maskelenmesini sağlar. Bu vakalarda geleneksel feldspatik porselen kullanımı durumunda rengin maskelenebilmesi için daha fazla diş preparasyonu gerekir. Bu da dentine ulaşmak, porselen kalınlığından dolayı rezin siman polimerizasyonunu azaltmak demektir. ${ }^{35}$ Materyalin opak olması rengi maskeleyebilmesinin yanında optik olarak doğal dişe yakın translüsensi göstermesini zorlaştırır. ${ }^{36}$ Zirkonya restorasyonu ince olursa translüsensi ve renk konusunda uyum sağlanmayabilir. Bu durumlarda siman rengi, zirkonya üzerindeki (servikal, orta üçlü, insizal kısım) renk seçimi için daha da önemlidir. ${ }^{37}$

- CAD/CAM sistemleri için geliştirilen seramikler

CAD/CAM yöntemiyle üretilen laminate restorasyonlar; feldspatik (silikat) seramik, lösit içerikli seramik, lityum disilikat seramik, rezin seramik, hibrit seramik, zirkonya katkılı lityum disilikat seramik, zirkonya katkılı lösit seramik ve monolitik zirkonya gibi çok çeşitli materyallerden üretilebilmektedir.
Silikat seramikler, kristalin fazdan ve doğal dişe yakın translüsent görünümü sağlayan cam fazdan oluşmaktadır. İstenilen translüsensi miktarına göre yüksek ve düşük translüsensiye sahip farklı renklerdeki silikat seramik bloklar üreticiler tarafından piyasaya sunulmuştur. ${ }^{38}$ Lityum disilikat seramikler ise, silikat seramiklerden daha yüksek mekanik özelliklere sahip olup, yüksek translüsensi, düşük translüsensi ve orta opasitedeki blok seçenekleri bulunmaktadır. ${ }^{38}$ Lityum disilikat seramiklerde, estetik görünümü sağlamak için seramik üzerinden bir miktar madde kaldırılarak veneerleme yapılabilmektedir. Ayrıca glaze işlemi sırasında gerekli ise renklendirme yapılabilmektedir. Son dönemde geliştirilen zirkonya katkılı lityum disilikat seramikler, cam fazın içerisinde \% 10 zirkonyum oksit içermekte olup lityum disilikat seramiklere alternatif olarak üretilmiştir. Zirkonya katkılı lityum disilikat seramikler, hidroflorik asitle pürüzlendirilebilmeleri ve silanlanabilmeleri nedeniyle adeziv simantasyon yapılabilmektedir. ${ }^{38,39}$ Hibrit seramikler, polimer ve seramikten oluşmaktadır. Polimer yapının ağırlıkça \%66' lık kısmını üretan dimetakrilat ve \%33' lük kısmını trietilen glikol dimetakrilat oluşturmaktadır. Seramik kısım ise ağırlıkça \%56-64 silisyum dioksitten oluşmaktadır. Hibrit seramiklerin kullanım endikasyonları silikat seramiklere benzemekte olup, asitle pürüzlendirilebilir ve silanlanabilirler. ${ }^{38}$ Hibrit seramikler, iyi kenar uyumları sayesinde çok ince kenarlarda kullanılabilirler. Bu özellikleri, çok az preparasyon yapılan veya preparasyon yapılmayan vakalarda kullanılabilmelerini sağlar. ${ }^{38}$ Rezin seramik materyaller, hibrit seramiklere benzemekte olup; yüksek ve düşük translüsensiye sahip renk seçenekleri mevcuttur. Ancak hibrit seramiklerin aksine, hidroflorik asit uygulaması etkili değildir. Bu materyallerin adeziv simantasyonunda kumlama önerilmektedir. ${ }^{38}$ Rezin nano seramik olarak piyasa sürülen Lava Ultimate, materyalin ağırlıkça \%80'ini oluşturan polimer matriks içerisine gömülmüş seramik partiküllerinden oluşmaktadır. ${ }^{39}$ Translüsensi seçeneği bulunan Lava Ultimate bloklar, iyi kenar uyumu nedeniyle preparasyon yapılmayan vakalarda da kullanılabilmektedir. ${ }^{39}$ Monolitik zirkonya restorasyonlar ise; veneerlenmeden kullanılan restorasyonlar olup, bazı vakalarda fasiyal yüzde veneerleme yapılabilmektedir. Estetik özelliklerinin geliştirilmesi amacıyla firmalar tarafından translüsent zirkonya bloklar üretilmektedir. Bu bloklar kendiliğinden renkli bloklar olabileceği gibi sinterizasyon öncesinde ve sonrasında da renklen- 
dirme yapılabilmektedir. Sinterizasyon öncesi renklendirme renk solüsyonlarının içerisine belli bir süre daldırma suretiyle yapılmaktadır. Sinterizasyon sonrasında yapılan renklendirme de ise çeşitli yüzey boyama porselenleri kullanımaktadır. ${ }^{38}$ Porselen laminate veneer yapımında kullanılan çeşitli materyaller ile yapılan çalışmalar Tablo 2'de özetlendi. 1,27,28,40-42

Tablo 2. Kullanılan materyallere göre yapılan çalışmalar

\begin{tabular}{|c|c|c|c|}
\hline Yazar & Çalışma & Kullanılan materyal & Sonuç \\
\hline Cho ve ark. ${ }^{40}$ & $\begin{array}{c}\text { Die spacer } \\
\text { kalınlığnın } \\
\text { simantasyona } \\
\text { etkisi }\end{array}$ & Feldspatik porselen & $\begin{array}{c}\text { Die spacer yapışma } \\
\text { dayanımını } \\
\text { arttırmaktadır. }\end{array}$ \\
\hline Chen ve ark. ${ }^{28}$ & \begin{tabular}{|c|} 
Farklı yüzey \\
işlemlerin \\
mekanik \\
pzelliklerine etkisi
\end{tabular} & \begin{tabular}{|c} 
CAD/CAM ile \\
şekillendirilen \\
VITABLOCKS Mark \\
2 (feldspatik \\
porselen)
\end{tabular} & $\begin{array}{c}\text { Glaze, parlatma } \\
\text { işlemleri materyalin } \\
\text { direncini } \\
\text { arttırmaktadır. }\end{array}$ \\
\hline Lin ve ark. ${ }^{41}$ & $\begin{array}{l}\text { Marjinal uyum ve } \\
\text { kırılma dayanımı }\end{array}$ & $\begin{array}{c}\text { CAD/CAM ile } \\
\text { şekillendirilen } \\
\text { Lösitle } \\
\text { güçlendirilmiş } \\
\text { seramik veneer } \\
\text { (ProCAD, İvoclar } \\
\text { Vivadent) } \\
\text { Feldspatik porselen } \\
\text { veneer (Noritake } \\
\text { Super Porcelain } \\
\text { EX3) }\end{array}$ & \begin{tabular}{|c|} 
Marjinal uyum ve \\
kırılma dayanımı \\
açısından geleneksel \\
interlenmiş feldspatik \\
porselen \\
önerilmektedir.
\end{tabular} \\
\hline $\begin{array}{c}\text { Aboushelib ve } \\
\text { ark. }^{1}\end{array}$ & \begin{tabular}{|c|} 
İnternal \\
adaptasyon ve \\
marjinal \\
özelliklerin yapım \\
yöntemlerine \\
göre \\
karşılaştırılması \\
\end{tabular} & $\begin{array}{l}\text { IPS e.max Press } \\
\text { IPS e.max CAD }\end{array}$ & \begin{tabular}{|c|} 
Preslenen \\
seramiklerin internal \\
adaptasyonu ve \\
marjinal uyumu daha \\
iyidir.
\end{tabular} \\
\hline $\begin{array}{c}\text { Alghazzawi ve } \\
\text { ark. }^{27}\end{array}$ & $\begin{array}{c}\beta \text { farklı materyalin } \\
\text { fiziksel } \\
\text { özelliklerinin } \\
\text { değerlendirilmesi }\end{array}$ & $\begin{array}{c}\text { Zirkonya } \\
\text { (CAD/CAM) } \\
\text { Lityum disilikat } \\
\text { cam seramik } \\
\text { (CAD/CAM) } \\
\text { Feldspatik porselen }\end{array}$ & \begin{tabular}{|l|} 
Zirkonyada yüksek \\
oranda ayrılma ve \\
düşük oranda kırılma \\
neydana gelmektedir. \\
Feldspatik porselende \\
yüksek oranda kırılma \\
neydana gelmektedir. \\
\end{tabular} \\
\hline $\begin{array}{c}\text { Bağış } \\
\text { veTurgut }\end{array}$ & $\begin{array}{l}\text { Yaşlandırma } \\
\text { prosedürü ile } \\
\text { farklı } \\
\text { materyallerin } \\
\text { karşılaştırılması }\end{array}$ & $\begin{array}{l}\text { IPS e.max Press } \\
\text { IPS Empress } \\
\text { Esthetic } \\
\text { IPS Zirpress } \\
\text { IPS e.max Ceram } \\
\text { IPS Inline } \\
\text { IPS e.max CAD } \\
\end{array}$ & \begin{tabular}{|c|} 
Renk seçiminde \\
seramik sistemlerin \\
kimyasal yapısı üretim \\
tekniklerinden daha \\
belirleyicidir.
\end{tabular} \\
\hline
\end{tabular}

Fons-Font ve ark. ${ }^{18}$ porselen laminate veneer restorasyonlarında doğru materyal seçiminin yapılabilmesi için hastaları sınıflandırmışlardır. Bu sınıflandırmaya göre;

Tip 1: Restorasyonun fonksiyonel yüklere maruz kalmadığı vakalardır.

Tip 1-A: Restorasyon yapılacak dişlerin renginin maskelenmesi gerekmeyen, fonksiyonel yüklere maruz kalmayan, basit estetik problemlere sahip olan hastalar.
Bu tip vakalarda geleneksel feldspatik seramikler, yüksek optik özelliklerinden dolayı en iyi estetik sonucu verirler. İnterinsizal mesafenin $2 \mathrm{~mm}$ ' den fazla olduğu durumlarda ise yüksek dirençli feldspatik seramiklerin kullanımı hem estetik hem de kırıma dayanımı açısından önerilir.

Tip 1-B: Restorasyon yapılacak dişlerin renginin maskelenmesi gerektiği, dişlerin parafonksiyonel yüklere maruz kalmadığı basit estetik problemlere sahip hastalar.

$\mathrm{Bu}$ tip vakalarda simanın ve porselenin rengini maskeleyebilmesi için bir miktar opak olması gereklidir. Bunun yanında iyi bir estetik sağlanabilmesi için maddenin translüsent olması da önemlidir. Diş preparasyonlarının biraz daha fazla $(0,8-1 \mathrm{~mm})$ yapılması ve diş etinin altında chamfer basamak şeklinde sonlanması gerekmektedir. Kullanılacak olan maddenin bir miktar opasiteye ve belirli bir dirence sahip olması gerekir.

Tip 2: Fonksiyonel yüklere maruz kalan vakalardır. Bu tip vakalarda yüksek dirençli feldspatik, alumina ve oksit seramikler endikedir.

Lin ve ark. ${ }^{41}$, CAD/CAM ile hazırlanan lösitle güçlendirilmiş seramik veneer ile geleneksel feldspatik porseleni karşılaştırdıkları çalışmada feldspatik porselenin kenar uyumunu daha başarılı bulmuşlardır. CAD/CAM ile şekillendirilen lösitle güçlendirilmiş cam seramiklerde hazırlanma aşamasında gerçekleşen vibrasyondan dolayı mesial yüzeyde distal yüzeye göre daha fazla adaptasyon problemleri gözlemlenmiştir. Alghazzawi ve ark. ${ }^{27}$ zirkonya, lityum disilikat cam seramik ve feldspatik porselenler arasında, zirkonyanın en fazla oranda ayrılma en az oranda kırılma gösterdiğini, feldspatik porselenlerin ise en az ayrılma en fazla oranda kırılma gösterdiğini bildirmişlerdir. Aboushelib ve ark. ${ }^{1}$ marjinal uyum, internal adaptasyon açısından presleme (IPS e.max Press) yöntemini, CAD/CAM (IPS e.max CAD) yöntemine göre daha başarılı bulmuştur.

\section{Porselen laminate veneerlerde preparasyon} şekilleri

Porselen laminate veneerlerde önemli başarı faktörlerinden birisi de kontrollü diş dokusu kaldırılmasıdır. ${ }^{16}$ Diş preparasyonu en iyi kenar uyumunu sağlamasının yanı sıra doğal diş morfolojisini sağlama imkanı da sunmalıdır. ${ }^{43}$ Minede tamamlanan preparasyon, rezin kompozitin bağlanma dayanıklıı̆ını arttırmaktadır. Dentinde sonlanan restorasyonlarda ise mikrosızıntı oluşmaktadır. ${ }^{11,12,19,33}$ 
Calamia ve Calamia ${ }^{44}$ derin preparasyonlarda açığa çıkan dentinin mineye göre daha düşük elastiklik katsayısından dolayı restorasyonun yerleşeceği alanın daha az rijit olacağı bunun da restorasyonun başarısını olumsuz etkileyeceğini rapor etmiştir. Yapılan çalışmalarda ayrılma hatalarının \%80' inin dentin yüzeyinde açığa çıktığı bildirilmektedir. ${ }^{2,8,15,35}$ Peumans ve ark. ${ }^{12}$ ise yaptığı çalışmada dentine ulaşan preparasyonun restorasyonun kalitesini düşürdüğü, dentin bağlayıcıların dentin kenarlarında oluşan mikrosızıntıyı uzun dönemde çözemediğini belirtmişlerdir. Bazı yazarlar preparasyonun mümkün olduğunca mine de sonlandırılması gerektiğini çünkü en iyi adezyon ve en iyi stres dağıımının mine-kompozit-porselen üçlüsünde olduğunu belirtmişlerdir. ${ }^{2,24}$ Dikkatli hazırlanan preparasyon, simantasyon, ölçü, yapım ve bitim teknikleri ile mikrosızıntı azaltılabilmektedir. ${ }^{33,45}$

Porselen laminate veneerlerde diş kesiminin 0,3-0,5 mm arasında yapılması halinde kesimin \% 95100 oranında minede sonlandırılabileceğini belirten çaIsşmaların yanında, 0,4-0,6 mm' lik bir kesimle servikal alanda dentinin açığa çıkabileceğini vurgulayan çalışmalar da vardır. $33,36,46,47$

Porselen laminate veneer restorasyonlarda tanısal mumlama yöntemi hem preparasyondan önce bitim aşamasının planlanabilmesine, hem de geçici restorasyon hazırlanabilmesine imkan sunar. Ayrıca tanısal mumlama kullanılarak, preparasyonun kontrollü şekilde yapılmasını sağlayan silikon indeks (mock-up) hazırlanır. ${ }^{48} \mathrm{Bu}$ yöntem, özellikle ince restorasyonlarda az diş kesimi gerektiğinde kullanılır. ${ }^{49,50}$ Silikon indeks yöntemi ile restorasyonun planlaması yapılabilir. ${ }^{51} \mathrm{Bu}$ yöntemin tamamlayıcı aşaması geçici restorasyonun hazırlanmasıdır. Bu sayede diş eti dokusunun korunması, oklüzal ve fonetik rahatlık sağlanır. ${ }^{50,52}$

Mine kalınlığı dişin servikal bölgesinden insizal bölgeye doğru değişmektedir. Dolayısıyla dentini açığa çıkarmamak için preparasyon derinliğini belirli bölgelerde değiştirmek gerekir. 0,7 mm önerilen kesim derinliği gingival kenara yakın bölgelerde $0,4 \mathrm{~mm}^{\prime}$ ye kadar azaltılabilir. İnsizal bölgelerde ise $1,5 \mathrm{~mm}^{\prime}$ ye çıkabilmektedir. ${ }^{9,52}$ Derinliği belirleyen bir işaret ile bu derinlik yakalanabilirken, bukkal alanda derinlik belirleyen frezlerle kesim öncesi hazırlık yapılabilmektedir. Preparasyonun dişin doğal şeklini taklit edebilmesi için bukkal kesim iki yüzey halinde hazırlanabilmektedir. ${ }^{16}$ Dişin rengi maskelenmesi gerektiği durumlarda aşırı sınırlara sahip bir restorasyon hazırlanmaması için yeterli derinlikte kesim yapılması gerekir. Bu kesimin dentine ulaşma riski dezavantaj oluşturur. Preparasyona başlamadan önce insizal kenarın preparasyona dahil edilip edilmeyeceğine karar verilmelidir. İnsizal kenar kesimi için 4 temel kesim prensibi vardır;

Window: Veneerin insizal kenara yakın şekilde sonlandığı preparasyon şeklidir. Bu preparasyon minede sonlanma imkanı verirken insizal kenarda kalan mine dokusunun zayıflamasına sebep olur. Veneer kenarları insizal aşınmalarda korunmasız kalabilir. ${ }^{16}$

Feather: Veneer insizal kenar sırtına kadar uzanır ama insizal kenardaki minenin tamamı kaldırılmaz. Bu preparasyon ile doğal dişin rehber kısmı korunur fakat özellikle ileri hareketlerde veneer kırılgandır. ${ }^{16}$

Bevel: Prerapasyon insizal kenarda bukko-palatal yönde ilerler. İnsizal kenardaki minenin yüksekliği bir miktar azaltılır. Bu preparasyon insizal kenarda estetik çalışma ve simantasyon sırasında dişe daha uyumlu oturma imkanı sağlar. İnsizal bitim sınırı, ileri hareketler sırasında makaslama kuvvetlerine maruz kalmaz ama bu kesim daha fazla mine dokusu kaldırmayı gerektirir. ${ }^{16}$

Overlap: İnsizal kenar, preparasyona tamamen dahil edilir ve veneer palatal yüzeye uzanır. Çok fazla diş dokusu kaldırıması gerekmesine rağmen simantasyon sırasında veneerin dişe tam uyumlu oturması sağlanır. Preparasyon esnasında proksimal kenarlarda girintili alanlar bırakılmaması gerekir. ${ }^{16}$

Window preparasyonunda mine-rezin simanporselen üçlüsünde adezyon sağlanmasına rağmen porselenin kırılma eğilimi vardır. ${ }^{2}$ Feather preparasyon prensibinde insizal kenarda mine korunabilmesine rağmen optik özellikleri insizal kenarda tam anlamıyla sağlamak zordur. ${ }^{24}$ İnsizal bölgede en iyi optik özelliklerin sağlanabilmesi için 1,5-2,0 mm porselen kalınıı̆ı olması ve overlap preparasyonun yapılması gerekmektedir. ${ }^{2,43}$

Aksiyel diş kesiminde paralel kenarlı torpil uçlu elmas frez kullanımı önerilmiştir. ${ }^{16}$ Bazı klinisyenler ilk olarak elmas rond frez kullanarak gingival kenarların chamfer tarzda şekillendirilmesini önermektedirler. Alternatif olarak torpil uçlu elmas frezlerle hem aksiyel hem de gingival kenarlar şekillendirilebilir. Geleneksel elmas frezler mine yüzeyinde pürüzlü alanlar oluşturur. Bu alanları pürüzsüzleştirmek için ince grenli frezler ya da tungsten-karbid bitirme frezleri kullanılabilir. Bu slrada gingival dokuyu korumak için retraksiyon yapılabilir. Bu retraksiyon ölçü alma işlemini de kolaylaştırır. ${ }^{2}$ 
Servikal bölgede gingival embrajürde kesim derinliğini, interdental papilla arasındaki renklenmeyi maskeleyebilmek için arttırmak gerekir. ${ }^{25,43}$ Veneer giriş yoluna uygun kesim yapmak bu bölgede önemlidir. Kontakt dişlere zarar vermeden dar çaplı frezlerle proksimal kenarlar prepare edilebilir. Proksimal bitim kenarlarının insizal üçlüde kontakt noktalarına kadar uzanması gerekir. ${ }^{2,16}$ Servikal bitim kenarlarında en fazla $0,4 \mathrm{~mm}$ kalınlığında chamfer basamak olmalıdır. Yuvarlak iç kenar açıları diş̧eti bitim sınııında stres oluşumunu engeller. Porselen bu sınıra tam uyumlu olacak şekilde hazırlanmalıdır. Preparasyon kenarı serbest diş eti tepesine uzanmalıdır. Ancak rengin maskelenmesi gereken bazı durumlarda subgingival kesim de gerekebilir. Bu kesimler estetik olarak başarıı sonuçlar verir. ${ }^{19} \mathrm{Li}$ ve ark. ${ }^{53}$ maksiller kesici dişlerde overlap ve feather preparasyon yöntemlerinin üç boyutlu sonlu elemanlar analizi ile stres dağılımını değerlendirdikleri çalışmalarında, oklüzal yükler altında overlap preparasyonun feather preparasyona göre minede ve veneer seramikte daha az stres dağılımı gösterdiğini bildirmiştir.

Stappert ve ark. ${ }^{15}$ maksiller santral dişte kontrol grubu, window, overlap ve tam veneer preparasyon yöntemlerinin kırııma dayanımlarıı değerlendirmiş, kırııma dayanımı yüksekten düşüğe doğru sırasıyla kontrol grubu, overlap, window ve tam veneer olarak bulunmuştur. Hahn ve ark. ${ }^{47}$ mandibular kesici dişlerde window ve overlap preparasyon şekillerinin kırıma dayanımını değerlendirdiği çalışmalarında overlap tasarımının daha başarılı sonuç verdiğini bildirmiştir. Schmidt ve ark. ${ }^{7}$ maksiller aşınmış ve aşınmamış santral dişlerde palatal bölgeye uzanan shoulder ve chamfer preparasyon şekillerini kırıma dayanımına göre değerlendirdikleri çalışmalarında, aşınmamış dişlerde kırıma dayanımı daha fazla bulunurken, palatal chamfer preparasyon daha yüksek kırıma dayanımı göstermiştir. Farklı preparasyon şekillerini içeren çalışmalar Tablo 3'te özetlendi. ${ }^{7,15,27,47,53-57}$

\section{Porselen laminate veneerlerde simantasyon}

Porselen laminate veneer restorasyonların klinik başarısı rezin siman aracılığıyla restorasyon ile diş yapısı arasında iyi bir bağlantı oluşmasına bağlıdır. $^{2,58,59}$ İyi bir bağlantının sağlanabilmesi için preparasyon sınırlarının minede sonlanması, doğru yüzey işlemlerinin uygulanması ve doğru kompozit rezin siman tercihi gerekmektedir. ${ }^{60}$ Porselen laminate veneer restorasyonlarda klinik başarı, yapıştırma sima- nının aşınmaya, mikrosızıntıya, renklenmeye ve kenar kırıklarına karşı hassas olmasından dolayı sınırıdır. Mikrosızıntı genellikle preparasyon sırasında dentinin

Tablo 3. Preparasyon şekline göre yapılan çalışmalar

\begin{tabular}{|c|c|c|c|}
\hline Yazar & Çalışma & $\begin{array}{c}\text { Preparasyon } \\
\text { Dizaynı }\end{array}$ & Sonuç \\
\hline $\begin{array}{l}\text { Hahn ve } \\
\text { ark. }\end{array}$ & $\begin{array}{c}\text { Farklı preparasyon } \\
\text { şekilleri ile kırılma } \\
\text { dayanımı } \\
\text { değerlendirme } \\
\text { (Empress, lösitle } \\
\text { güçlendirilmiş cam } \\
\text { seramik) }\end{array}$ & $\begin{array}{l}\text { Kesimsiz } \\
\text { örnek } \\
\text { Window } \\
\text { Overlap }\end{array}$ & $\begin{array}{l}\text { Window preparasyon } \\
\text { daha yüksek kırılma } \\
\text { dayanımı göstermiştir. }\end{array}$ \\
\hline $\begin{array}{l}\text { Stappert ve } \\
\text { ark. }^{15}\end{array}$ & $\begin{array}{c}\text { Farklı } \\
\text { preparasyonların } \\
\text { kırılma tokluğu } \\
\text { değerlendirilmesi }\end{array}$ & $\begin{array}{l}\text { Window } \\
\text { Overlap } \\
\text { Full veneer }\end{array}$ & $\begin{array}{c}3 \text { preparasyonda } \\
\text { kırılma dayanımı doğal } \\
\text { dişe yakın } \\
\text { bulunmuştur. }\end{array}$ \\
\hline $\begin{array}{c}\text { Vasconcelo } \\
\text { s ve } \text { ark. }^{54}\end{array}$ & $\begin{array}{l}\text { Anatomik rehber } \\
\text { değerlendirilmesi }\end{array}$ & $\begin{array}{l}\text { Servikalde } \\
\text { chamfer } \\
\text { basamak }\end{array}$ & $\begin{array}{c}\text { Anatomik rehber } \\
\text { kullanılarak hazırlanan } \\
\text { restorasyonlar daha az } \\
\text { overkonturludur. }\end{array}$ \\
\hline $\begin{array}{c}\text { Schmidt ve } \\
\text { ark. }^{7}\end{array}$ & $\begin{array}{c}\text { Aşınmış ve } \\
\text { aşınmamış dişlerde } \\
\text { farklı preparasyon } \\
\text { şekilleri kırıma } \\
\text { dayanımını } \\
\text { değerlendirme }\end{array}$ & $\begin{array}{l}\text { Aşınmış ve } \\
\text { aşınmamış } \\
\text { palatal } \\
\text { chamfer } \\
\text { Aşınmış ve } \\
\text { aşınmamış } \\
\text { palatal } \\
\text { shoulder }\end{array}$ & $\begin{array}{c}\text { Aşınmış dişler başarıyı } \\
\text { olumsuz } \\
\text { etkilemektedir. } \\
\text { Palatal chamfer, } \\
\text { shoulder } \\
\text { preparasyona göre } \\
\text { daha yüksek kırılma } \\
\text { dayanımı } \\
\text { göstermektedir. }\end{array}$ \\
\hline $\begin{array}{l}\text { Shetty ve } \\
\text { ark. }^{55}\end{array}$ & $\begin{array}{c}\text { Farklı preparasyon } \\
\text { şekillerinin başarı } \\
\text { oranlarının } \\
\text { değerlendirilmesi }\end{array}$ & $\begin{array}{l}\text { Window } \\
\text { Overlap } \\
\text { Bevel }\end{array}$ & $\begin{array}{l}\text { 1) En konservatif } \\
\text { window tipidir. } \\
\text { 2) İnsizal kesim, } \\
\text { insizal kesimsize göre } \\
\text { daha başarılıdır. } \\
\text { 3)Aşınmamıs dişlerde } \\
\text { overlap ve aşınmış } \\
\text { dişlerde bevel } \\
\text { önerilmektedir. }\end{array}$ \\
\hline $\begin{array}{l}\text { Archangelo } \\
\text { ve } \text { ark. }^{56}\end{array}$ & $\begin{array}{l}\text { Premolar dişte } \\
\text { farklı kesim } \\
\text { prensipleri ve } \\
\text { stres dağılımı } \\
\text { değerlendirilmesi }\end{array}$ & $\begin{array}{c}\text { Bevel } \\
\text { Overlap }\end{array}$ & $\begin{array}{c}\text { Anlamlı fark } \\
\text { bulunamamıştır. }\end{array}$ \\
\hline $\begin{array}{c}\text { Alghazzawi } \\
\text { ve ark. }{ }^{27}\end{array}$ & $\begin{array}{c}\text { İki farklı } \\
\text { preparasyon } \\
\text { kırılma dayanımı } \\
\text { değerlendirilmesi }\end{array}$ & $\begin{array}{c}\text { Overlap } \\
\text { Kontakt } \\
\text { noktaları } \\
\text { kaldırılmış } \\
3 \text { yüzey } \\
\text { overlap }\end{array}$ & $\begin{array}{l}\text { Kırılma dayanımı } \\
\text { olarak anlamlı fark } \\
\text { bulunamamıştır. }\end{array}$ \\
\hline $\begin{array}{l}\text { Da Costa } \\
\text { ve ark. } 57\end{array}$ & $\begin{array}{c}\text { Farklı preparasyon } \\
\text { yöntemlerinin } \\
\text { kırılma dayanımına } \\
\text { etkisi }\end{array}$ & $\begin{array}{l}\text { Feather } \\
\text { Overlap } \\
\text { Bevel }\end{array}$ & $\begin{array}{c}\text { En yüksek kırılma } \\
\text { dayanımı bevel } \\
\text { tipinde, } \\
\text { En düşük kırılma } \\
\text { dayanımı overlap tipi } \\
\text { preparesyondadır. }\end{array}$ \\
\hline Li ve ark. ${ }^{53}$ & $\begin{array}{c}\text { İki farklı } \\
\text { preparasyon } \\
\text { şeklinde stres } \\
\text { dağılımı }\end{array}$ & $\begin{array}{l}\text { Overlap } \\
\text { Feather }\end{array}$ & $\begin{array}{l}\text { Overlap daha iyi stres } \\
\text { dağılımı göstermiştir. }\end{array}$ \\
\hline
\end{tabular}

açığa çıkması durumunda sıklıkla görülmektedir. ${ }^{61} \mathrm{Az}$ preparasyon ile hazırlanmış porselen laminate veneer restorasyonların yapıştııımasında hem diş yapısına hem de porselen yüzeyine çeşitli uygulamalar yapılır. ${ }^{62}$ Restorasyonun simantasyon işleminde porselen

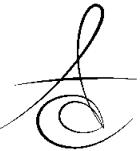


yüzeyine fosfat florit veya hidroflorik asit uygulaması, aluminyum oksit abrazyon uygulaması, silan uygulaması yapılırken diş yüzeyine asit uygulaması, primer uygulaması veya lazer işlemi yapılır. 58,62-64

Minede asitleme başarılı şekilde kullanılmaktadır. Ancak dentine simantasyon mineye simantasyon kadar başarılı değildir. ${ }^{62,65,66}$ Mine tabakası dentine göre daha az geçirgen olduğundan mikrosızıntı, postoperatif hassasiyet, sekonder çürük, pulpal enflamasyon oluşma riski daha azdır. ${ }^{63-65,67,68}$ Buna karşın dentine simantasyon, demineralize dentin tabakası nedeniyle daha karmaşıktır. ${ }^{64}$

Günümüzde adeziv sistemlerinin (asitle ve yıka veya kendinden asitli sistemler) amacı yüzey pürüzlülüğünü arttırmak ve mekanik retansiyon sağlamaktır. ${ }^{62,63,65,69-71}$ Asitle ve yıka (total etch) adeziv sistemlerinde primer uygulanmadan önce mine ve dentine fosforik asit uygulanır. Mine asitlenmesi inorganik mine yüzeyinde mikroporoziteler oluşturarak mekanik bağlanma imkanı sunar. ${ }^{69,72}$ Dentinde asitleme ise smear tabakasını kaldırır ve dentin tübüllerini açar. ${ }^{72}$ Aşırı asitleme kollajen fiberlerin bozulmasına sebep olur, hibrit tabakanın bütünlüğünü bozar, monomerlerin tamamen yüzeye yapışmasına veya polimerize olmasına engel olur. ${ }^{73-75}$

Kendinden asitli (self-etch) adeziv sistemlerinde asitleme basamağı ayrılmadığından, fosforik asitten oluşan sulandırımış asidik monomerler kullanılır. ${ }^{73} \mathrm{Bu}$ sistemler smear tabakasını tamamen kaldırmaz bu da tedavi sonrasında hassasiyeti azaltır. ${ }^{62,76-78} \mathrm{Bu}$ sistemler nem kontrolü gerektirmez.

Minenin iç yüzeyindeki lekeli poröz yapılar restorasyonun optik özelliklerini olumsuz etkiler. Asit uygulanarak yapılan mine aşındırılması bu poröz yapıların kaldırılmasını sağlar. Beyaz opak alanları, kahverengi lekeleri elimine eder ve yüzey düzensizliklerini düzetir. ${ }^{79,80}$ Ancak ince mine tabakasında sarımsı veya homojen olmayan renklenmelere sebep olur. ${ }^{81} \mathrm{Bu}$ renk düzensizlikleri vital beyazlatma işlemi ile düzetilir ve homojen beyaz mine tabakası elde edilir. ${ }^{82}$ Mine ve dentin yüzeyi pürüzlendirmelerinde asit uygulamaya alternatif olarak lazer sistemler kullanılabilir. ${ }^{63,83}$ Lazer Işınlama, ISI ve vibrasyon oluşturmayan daha acISIZ işlemlerdir. Lazer ile adezyon için ideal olan, dentin tübüllerinin açılması ve mine yüzeyinde pürüzlü yüzey oluşmasının sağlanmasıdır. ${ }^{84}$

Porselen yüzeyine uygulanan porselen-siman bağlantısını güçlendirmek amacıyla yapılan yüzey işlemleri; kimyasal olarak fosfat florid ${ }^{65}$ veya hidroflorik asit $^{58,65}$ veya aluminyum oksit ile pürüzlendirmedir. ${ }^{58}$ Porselen yüzeyine asit uygulaması porselen yüzeyinde pürüzlülük sağlayarak porselen ile siman arasında mekanik bağlanma oluşmasını amaçlar. ${ }^{85}$ Ancak uygulanan asitin uzun süre uygulanması veya fazla konsantrasyonda olması porselenin fiziksel özelliklerini azaltır. ${ }^{86}$ Porselen yüzeyine mekanik olarak uygulanan alumina abrazyon işlemleri ise hidroflorik asit uygulamalarından daha güvenli ve kolay uygulanabilir ve daha ucuzdur. ${ }^{58}$

Porselen laminate veneer simantasyonunda ışınla polimerize olan veya hem ışın hem kimyasal polimerize olan dual cure rezin simanlar kulanıIır. ${ }^{33,60,87} \mathrm{Hem}$ ışınla hem kimyasal polimerize olan rezin simanlar fazla akıcıdır ve iki komponentin karışımından oluşmasından dolayı porozite oluşturabilir bu da mikrosızıntı olasılığını arttıır. ${ }^{60}$ Işınla polimerize olan rezin simanın, kimyasal veya hem ışınla hem de kimyasal polimerize olan rezin simanlara göre en önemli avantajı uzun çalışma süresidir. ${ }^{2,84} \mathrm{Bu}$ özellik restorasyonun kenarında kalan siman artıklarının kolayca temizlenmesini sağlar. Bunun yanında ışınla polimerize olan rezin simanın renk stabilitesi diğer rezin simanlara göre daha iyidir. ${ }^{87}$ Ancak rezin simanın polimerizasyon sırasında yeterli ışını abzorbe etmesi önemlidir. Porselen veneerler \%40-50 arasında ışını abzorbe eder. Bu yüzden porselen kalınlığı ışın abzorbsiyonu nedeniyle simanın polimerizasyonu için önemli etkendir. ${ }^{88,89}$ Opasite ve porselen rengi ışın abzorbsiyonu için kalınlığa göre daha az öneme sahiptir. ${ }^{12,70}$ 0,7 mm'den daha fazla porselen kalınlığında ışınlanan rezin simanın en yüksek sertliğe ulaşmadığı bildirilmiştir. ${ }^{12} \mathrm{Bu}$ durumlarda hem ışınla hem de kimyasal polimerize olan dual cure rezin simanların kullanımı önerilmektedir. $^{2}$ Dual cure rezin simanlar yüksek mekanik özellikleri ve akışkanlıkları sebebiyle porselen laminate restorasyonlarında kulla- nılmaktadır. ${ }^{50}$ Ancak kimyasal ve dual cure rezin simanlar tersiyer amin içeriğinden dolayı uzun dö- nemde renk değişimine uğrar. Bu durum özellikle ince restorasyonların estetik görünümünü olumsuz etkiler. ${ }^{90-92}$

Porselen laminate restorasyonlarda daimi restorasyon hazırlanana kadar geçici restorasyonlar kullanılır ancak geçici simantasyon işlemleri kalıcı restorasyonların simantasyon başarısını etkiler. ${ }^{93}$ Hassasiyet giderici simanlar geçici simantasyonda sıkIıkla kullanılmaktadır ancak bu simanların kalıcı

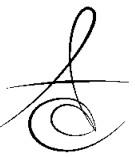


simantasyona olumsuz etkisi vardır. ${ }^{60}$ Bazı çalışmalarda ojenol içermeyen simanların daimi simantasyona etkisi olmadığı belirtilmiştir. ${ }^{62}$ Diğer yandan Dumfahrt ve ark. ${ }^{94}$ hassasiyet giderici rezin simanlarla geçici simantasyonun, daimi simantasyonda primer asit uygulamasına olumsuz etki edebildiğini bildirmiştir.

Porselen laminate restorasyonların uzun dönem başarısı için, simantasyon işleminin dikkatli ve titiz yapılması gerekir. Başarısız bir simantasyon dentin ve siman arasında mikrosızıntı oluşumuna ${ }^{52,84,95}$, sekonder çürüklere, marjinal bölgede renklenmelere, restorasyonda kırılmalara sebep olur. ${ }^{54,83}$ Porselen laminate veneerlerde simantasyonu içeren çalışmalar Tablo 4 'te özetlendi. ${ }^{58,60,62,84,86,93,96-99}$

\section{Porselen laminate veneerlerde başarı oranları}

Porselenin esneklik katsayısının düşük olması, dentin yüzeyine adezyon, büyük defekt veya kompozit dolgulara sahip dişlere simantasyon, ağır fonksiyonel ve parafonksiyonel yükler, tam seramik restorasyonların başarısını olumsuz etkiler. ${ }^{17,22,33}$ Bunun yanında adeziv kompozit materyalin polimerizasyon büzülmesi sonucu oluşan stresler veya travmatik oklüzal yükler de porselen kırımalarına sebep olur. ${ }^{22}$ Dikkatli hasta seçimi, palatal bölgede mini-chamfer veya butt-joint basamak oluşturularak yapılan kontrollü diş preparasyonu, ${ }^{26}$ seramik kalınlığının $1 / 3$ oranını geçmeyecek şekilde hazırlanan rezin siman kalınlığı, ${ }^{14}$ antagonist dişle oluşan temasın kontrolü ise kırık oluşum riskini azaltmaktadır. ${ }^{33}$ Porselen laminate veneer restorasyonların en önemli başarısızıkları kırıma, mikrosızıntı ve ayrılma olarak belirtilmiştir. ${ }^{17,19,22}$ Yapılan farkı çalışmalarda laminate veneer başarı oranları \%53 $\% 98$ arasında değişmektedir. ${ }^{17,22,28,100,101}$ Meijering ve ark. ${ }^{102}$ porselen laminate restorasyonlarda başarı oranını \% 94, indirekt kompozit veneer restorasyonlarda başarı oranını $\% 90$, direkt kompozit veneer restorasyonlarında başarı oranını ise $\% 74$ olarak bildirmişlerdir.

Dentine simante edilen laminate veneer restorasyonun daha az sert yapıda olması yüklemeler sırasında daha fazla stres oluşumuna sebep olur. ${ }^{103}$ Küçük kopma (chipping) şeklindeki kırımalar ise ince yapısından dolayı insizal bölgelerde görülmektedir. ${ }^{12}$ Gingival üçlüde görülen kırılmaların sebebi ince mine kalınığından dolayı preparasyonun dentine ulaşmasıdır. ${ }^{104}$ Preparasyon sınırlarının minede sonlandığı restorasyonların başarı oranları 5 ylllık çalışmada \% 97 olarak bildirilirken, ${ }^{105} 12$ yllık çalışmada \% 94 olarak bildirilmiştir. ${ }^{106}$ Burke $^{17}$ ise 1993 ile 2009 arasında porselen laminate veneer restorasyonların başarı oranTablo 4. Simantasyon türüne göre yapılan çalışmalar

\begin{tabular}{|c|c|c|c|}
\hline Yazar & Amaç & Siman tipi & Sonuç \\
\hline $\begin{array}{l}\text { Usumez ve } \\
\text { ark. }^{84}\end{array}$ & $\begin{array}{c}\text { İki farklı ışın } \\
\text { kaynağının } \\
\text { karşılaştırılması }\end{array}$ & $\begin{array}{c}\text { Halojen, } \\
\text { Plazma ark }\end{array}$ & $\begin{array}{l}\text { Polimerizasyon açısından } \\
\text { halojen ışık kaynağı, } \\
\text { plazma ark ışık kaynağına } \\
\text { göre daha iyidir. }\end{array}$ \\
\hline $\begin{array}{l}\text { Fleming ve } \\
\text { ark. }^{58}\end{array}$ & \begin{tabular}{|} 
Alumina abrazyon \\
yönteminin yüzey \\
pürüzlülüğg̈üne \\
etkisi
\end{tabular} & Rezin siman & $\begin{array}{c}\text { Alümina partikülleri } \\
\text { büyüdükçe yüzey } \\
\text { pürüzlülüğü azalmaktadır. }\end{array}$ \\
\hline $\begin{array}{l}\text { Aykent ve } \\
\text { ark. }^{60}\end{array}$ & \begin{tabular}{|c|} 
Farklı geçici \\
simantasyon \\
işlemlerinin daimi \\
simantasyona \\
etkisi
\end{tabular} & $\begin{array}{c}\text { Ojenol } \\
\text { içermeyen } \\
\text { siman, Rezin } \\
\text { siman }\end{array}$ & $\begin{array}{l}\text { Daimi simantasyon için en } \\
\text { çok olumsuz etkiyi geçici } \\
\text { simantasyonda rezin siman } \\
\text { kullanımı oluşturmaktadır. }\end{array}$ \\
\hline $\begin{array}{c}\text { Addison ve } \\
\text { ark. }{ }^{86}\end{array}$ & $\begin{array}{l}\text { HF yüzey } \\
\text { pürüzlendirme } \\
\text { işleminin } \\
\text { simantasyon } \\
\text { başarısına etkisi }\end{array}$ & $\begin{array}{c}\text { HF asit } \\
\text { Oran: } \% 5,10, \\
20 \\
\text { Süre: } 45,90, \\
180 \text { sn. } \\
\end{array}$ & $\begin{array}{c}\text { Materyal özellikleri de göz } \\
\text { önüne alınarak \% } 10-20 \\
\text { oranında } 90 \text { sn HF } \\
\text { uygulanması } \\
\text { önerilmektedir. }\end{array}$ \\
\hline $\begin{array}{l}\text { Piemjai ve } \\
\text { ark. }{ }^{65}\end{array}$ & $\begin{array}{l}\text { Mine ve dentinde } \\
\text { farklı rezin } \\
\text { simanların etkisi }\end{array}$ & $\begin{array}{l}\text { All -Bond 2+ } \\
\text { Choice } \\
\text { Panavia21 } \\
\text { Scotchbond+ } \\
\text { Opal } \\
\text { SuperbondCB }\end{array}$ & $\begin{array}{l}\text { Minede sonlanan kesim } \\
0,5 \mathrm{~mm}>\text { dentinde sonlanan } \\
1 \mathrm{~mm} \text {. } \\
\text { Superbond CB en iyi } \\
\text { simantasyonu } \\
\text { göstermektedir. }\end{array}$ \\
\hline $\begin{array}{l}\text { Ratnaweera } \\
\text { ve ark. }{ }^{96}\end{array}$ & $\begin{array}{c}\text { Florozis } \\
\text { hastalığının } \\
\text { simantasyona } \\
\text { etkisi }\end{array}$ & $\begin{array}{c}\text { Rely/X } \\
\text { Clapearl }\end{array}$ & $\begin{array}{c}\text { Florozisin simantasyon } \\
\text { dayanımına etkisi yoktur. } \\
\text { Uzun asitleme süresine } \\
\text { gerek yoktur. } \\
\text { Siman çeşitleri arasında } \\
\text { fark yoktur. }\end{array}$ \\
\hline $\begin{array}{l}\text { navam ve } \\
\text { ark. }{ }^{97}\end{array}$ & $\begin{array}{l}\text { Polimerizasyon } \\
\text { tipinin } \\
\text { yaşlandırmaya } \\
\text { bağlı olarak } \\
\text { opasiteye etkisi } \\
\end{array}$ & \begin{tabular}{|c|} 
Light cure \\
Otopolimerizan \\
Dual cure
\end{tabular} & $\begin{array}{l}\text { Yaşlanmaya bağlı en çok } \\
\text { opasite } \\
\text { otopolimerizan> light } \\
\text { cure }>\text { dual cure }\end{array}$ \\
\hline $\begin{array}{c}\text { Turgut ve } \\
\text { Bagis }^{98}\end{array}$ & $\begin{array}{c}\text { Farklı rezin } \\
\text { simanların renge } \\
\text { etkisi }\end{array}$ & \begin{tabular}{|c|} 
Variolink \\
veneer, Rely X \\
veneer \\
Maxcem Elite, \\
Variolink 2 \\
\end{tabular} & $\begin{array}{l}\text { Siman tipi ve markasının } \\
\text { uzun dönem renk } \\
\text { değişimine etkisi yoktur. }\end{array}$ \\
\hline $\begin{array}{l}\text { Altıntas ve } \\
\text { ark. }^{93}\end{array}$ & $\begin{array}{c}\text { Farklı geçici siman } \\
\text { tiplerinin son } \\
\text { simantasyona } \\
\text { etkisi }\end{array}$ & \begin{tabular}{|c|} 
Kalsiyum \\
hidroksit \\
pjenolsüz geçici \\
siman \\
şınla polimerize \\
siman
\end{tabular} & \begin{tabular}{|c|} 
Son simantasyon \\
dayanımına en çok olumsuz \\
etki: ışınla polimerize \\
simanda görülmüştür. \\
Geçici simantasyon için \\
CaOH önerilmiştir.
\end{tabular} \\
\hline $\begin{array}{l}\text { Turgut ve } \\
\text { Bağış }\end{array}$ & $\begin{array}{l}\text { Farklı tip ve renkte } \\
\text { simanın ve farklı } \\
\text { kalınlık ve renkte } \\
\text { porselenin son } \\
\text { renge etkisi }\end{array}$ & \begin{tabular}{|c|} 
Şınla: Variolink, \\
Rely X \\
Hem ışın hem \\
kimyasal: \\
Maxcem, \\
Variolink 2 \\
\end{tabular} & $\begin{array}{c}\text { Simanlar istenmeyen renk } \\
\text { farklılıklarına yol } \\
\text { açmaktadır. } \\
\text { Porselen akışkanlığı } \\
\text { azaldıkça renge etkisi } \\
\text { artmaktadır. } \\
\end{array}$ \\
\hline
\end{tabular}

Iarını araştıran 24 makaleyi derlediği çalışmada dentine simantasyonun başarı oranını düşürdüğünü bildirmiştir. Magne ve Belser ${ }^{52}$ ve Fradeani ve ark. ${ }^{46}$ restorasyonlarda insizal kesimin bevel tarzda yapılması gerektiğini bildirirken, bazı yazarlar yanlı̧ simantasyon tekniklerinin restorasyonların başarısını etkilediğini

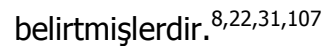


Beier ve ark. ${ }^{22}$ porselen laminate veneer restorasyonların konservatif ve başarilı restorasyonlar olduklarını belirtirken 10 yıllık başarı oranını \%93,5 olarak bildirmişlerdir. Bruksizm varlığında ve canlı olmayan dişlerde başarı oranının daha düşük olduğunu belirtmişlerdir. Dumfahrt ve Schaffer ${ }^{19} 191$ porselen laminate restorasyonların 10 ylllık klinik takibinde;

1- Başarı oranını ilk 5 yılda \%97, ilk 10 yılda \%91 oranında olduğunu,

2- Başarı oranının dolgu varlığında veya restorasyonun dentine simante edildiğinde düştüğünü,

3- Oklüzyonun başarısızıkta en önemli sebebin olduğunu,

4- Restorasyon kenarının dentinde sonlandığı durumlarda marjinal aralanma ve renklenmenin daha fazla olduğunu,

5- En zayıf bağlantının dentin-rezin siman arasında oluştuğunu tespit etmişlerdir.

Diğer bir 10 yıllık klinik takip çalışmasında 25 hastaya ait 87 porselen laminate veneer restorasyonun, 5 yılda $\% 92$ oranında, 10 yılda $\% 64$ oranında klinik olarak kabul edilebilir durumda olduğu belirtilmiştir. ${ }^{31}$ Bu çalışmada porselen kırılması ve büyük defektler başarısızlığın en önemli faktörleri olarak bildirilmiş ve restorasyonların sadece \%4'ünün tekrar simante edilmesi gerekliliği vurgulanmıştır.

Burke ve Lucarotti ${ }^{13}$, İngiltere ve Galler' de bulunan Diş Hekimliği Klinikleri'nde uygunlanmış porselen laminate veneer restorasyonlara sahip 1177 hastada yaptıkları 10 yıllık takip çalışması sonucunda, başarı oranlarını \%53 olarak bildirmişlerdir. Bu çalışma sonuçları; başarı oranını yaş cinsiyet gibi değişik hasta faktörlerinin etkilediğini, diş hekimi faktörünün daha az bir etkiye sahip olduğunu göstermiştir.

Granell-Ruiz ve ark. ${ }^{105}$ yaptığı çalışmada restorasyonun ayrılma oranını \%9 olarak belirtilmiştir. Bunun sebebi olarak da bruksizm, restorasyon yapilan dişin daha önceden kompozit dolgu ile restore edilmesi ve dentine simantasyon olarak bildirilmiştir. Gresnigt ve ark. ${ }^{49}$ ise 22 hastada 92 feldspatik porselen laminate restorasyonun 22 aylık takibi sonucunda; daha önce kompozit dolgu bulunan restorasyonlarda $\% 93,5$, kompozit dolgu bulunmayan restorasyonlarda \%96 başarı oranı saptamışlardır.

Bazı yazarlar parafonksiyonel hareketler (bruksizm) mevcudiyetinde başarısızlık oranının artacağından dolayı bu restorasyonların kontrendike olduğunu savunmuşlardır. ${ }^{12,24}$ Granell-Ruiz ve ark. ${ }^{101}$ porselen veneer restorasyonlarda kırıma oranını \% 4 olarak belirtmişlerdir. Christensen ${ }^{11} 3$ yılda $\% 87$, Walls ve ark. ${ }^{16}$ 5 yılda \%95 klinik başarı oranları bildirmişlerdir. Bu oranların sebeplerini bruksizm ve geleneksel feldspatik porselen kullanımına bağlı olduğunu açıklamışlardır. Porselen laminate veneerlerdeki başarı oranları ile ilgili çalışmalar Tablo 5 'te gösterildi. $13,22,28,29,31,62,101,103,105,106,108-110$

Tablo 5. Porselen laminate veneerlerde başarı oranları

\begin{tabular}{|c|c|c|c|}
\hline Yazar & $\begin{array}{l}\text { Çalışm } \\
\text { a } \\
\text { Süresi } \\
\end{array}$ & Başarı oranı & Sonuç \\
\hline $\begin{array}{l}\text { Peumans ve } \\
\text { ark. }^{31}\end{array}$ & $10 \mathrm{yll}$ & $\begin{array}{c}\text { Kayıp yok. } \\
\% 64 \text { klinik olarak } \\
\text { kabul edilebilir }\end{array}$ & $\begin{array}{l}\text { Dentine simantasyon } \\
\text { başarısızlık sebebidir. }\end{array}$ \\
\hline $\begin{array}{l}\text { Chen ve } \\
\text { ark. }^{28}\end{array}$ & $2,5 \mathrm{yll}$ & $\begin{array}{c}\text { İlk } 6 \text { ay } \\
\text { marjinal } \\
\text { renklenme } \% 5 \\
\text { postoperatif } \\
\text { hassasiyet \% } 25 \\
2,5 \text { yll marjinal } \\
\text { uyum sorunu \% } \\
19 \text { renklenme \% } 6 \\
\end{array}$ & $\begin{array}{l}\text { PLV restorasyonlar } \\
\text { tetrasiklin } \\
\text { renklenmerinde başarılı } \\
\text { sonuç vermektedir. }\end{array}$ \\
\hline $\begin{array}{l}\text { Murphy ve } \\
\text { ark. }^{106}\end{array}$ & $5 \mathrm{yll}$ & $\% 89$ & $\begin{array}{c}\text { Başarısızlık sebebi } \\
\text { kompozit dolgulardır. }\end{array}$ \\
\hline $\begin{array}{l}\text { Layton ve } \\
\text { Walton }^{29}\end{array}$ & $16 \mathrm{yll}$ & $\begin{array}{l}12 \text { yıl \% } 91 \\
15 \text { yıl } \% 73 \\
\end{array}$ & $\begin{array}{c}\% 80 \text { oranında minede } \\
\text { sonlanmaktadır. }\end{array}$ \\
\hline $\begin{array}{l}\text { Guess ve } \\
\text { Stappert }^{108}\end{array}$ & $5 \mathrm{yll}$ & $\begin{array}{l}\% 97 \text { overlap } \\
\text { preparasyon }\end{array}$ & $\begin{array}{c}\text { Dentine adezyon ve } \\
\text { kompozit dolgu } \\
\text { başarısızlık oranını } \\
\text { arttırmaktadır. } \\
\end{array}$ \\
\hline $\begin{array}{l}\text { Çötert ve } \\
\text { ark. }^{109}\end{array}$ & $\begin{array}{c}67 \\
\text { hafta }\end{array}$ & $\% 94$ & $\begin{array}{l}\text { En önemli sebep } \\
\text { ayrılmadır. }\end{array}$ \\
\hline $\begin{array}{c}\text { Burke ve } \\
\text { Lucarotti }^{13}\end{array}$ & $10 \mathrm{yll}$ & $\% 53$ & $\begin{array}{l}\text { Yaş, cinsiyet, hasta } \\
\text { faktörleri başarııı } \\
\text { etkilemektedir. }\end{array}$ \\
\hline $\begin{array}{l}\text { Aykor ve } \\
\text { Özel }^{62}\end{array}$ & $5 \mathrm{yll}$ & - & $\begin{array}{c}300 \text { restorasyon } \\
\text { minede sonlanmıştır. } \\
\text { Total etch-self etch } \\
\text { fark yoktur. }\end{array}$ \\
\hline $\begin{array}{l}\text { Grannel-Ruiz } \\
\text { ve ark. }{ }^{101}\end{array}$ & $11 \mathrm{yll}$ & $\begin{array}{c}\text { Hassasiyet ve } \\
\text { sekonder çürük \% } \\
3,1 \text { Marjinal } \\
\text { uyumsuzluk } \% 2 \\
\text { Kırılma } \% 4 \\
\text { Ayrılma } \% 9 \\
\end{array}$ & $\begin{array}{l}\text { Bruksizm başarı oranını } \\
\text { etkilemektedir. }\end{array}$ \\
\hline $\begin{array}{l}\text { Beier ve } \\
\text { ark. }\end{array}$ & $10 \mathrm{yll}$ & $\% 93,5$ & $\begin{array}{c}\text { En fazla görülen } \\
\text { başarısızlık kırılmadır. } \\
\text { Bruksizm ve kompozit } \\
\text { dolgu başarısızlık } \\
\text { sebebidir. }\end{array}$ \\
\hline $\begin{array}{l}\text { Gresnight ve } \\
\text { ark. }^{103}\end{array}$ & 40 ay & $\begin{array}{c}\text { Başarı oranı \% } 96 \\
\text { Marjinal } \\
\text { renklenme \% } 13 \\
\text { Marjinal defekt \% } \\
18 \text { Sekonder } \\
\text { çürük, endodontik } \\
\text { komplikasyon \% } 0\end{array}$ & $\begin{array}{c}\text { Kompozit dolgu } \\
\text { başarıyı etkilemektedir. }\end{array}$ \\
\hline $\begin{array}{l}\text { Grannell- } \\
\text { Ruiz ve } \\
\text { ark. }^{105}\end{array}$ & $12 \mathrm{yll}$ & $\begin{array}{c}\text { Ayrılma } \\
\text { Bruksizm \% 12,9 } \\
\text { Bruksizm olmayan } \\
\% 4,6 \\
\end{array}$ & $\begin{array}{l}\text { Splint kullanımı başarı } \\
\text { oranını arttırmaktadır. }\end{array}$ \\
\hline $\begin{array}{l}\text { Alhekeir ve } \\
\text { ark. }^{110}\end{array}$ & $2 \mathrm{yll}$ & $\% 65$ başarı oranı & $\begin{array}{l}\text { Başarısızlığın \% 60'ı } \\
\text { renk değişimidir. }\end{array}$ \\
\hline
\end{tabular}




\section{SONUÇ}

Porselen laminate veneerler, anterior ön bölge dişlerinde boyut, renk veya pozisyon değişikliğine gerek duyan hastalarda uygulanan konservatif restorasyonlardır.

Başarılı bir restorasyon için doğru endikasyon konulmalı, endikasyona ve hasta profiline uygun materyal ve rezin siman seçimi yapılarak preparasyonun mümkün olduğunca mine sınırları içerisinde sonlandırılması gerekmektedir.

\section{KAYNAKLAR}

1. Aboushelib MN, Elmahy WA, Ghazy MH. Internal adaptation, marginal accuracy and microleakage of a pressable versus a machinable ceramic laminate veneers. J Dent 2012;40:670-7.

2. Pini NP, Aguiar FH, Lima DA, Lovadino JR, Terada RS, Pascotto RC. Advances in dental veneers: materials, applications, and techniques. Clin Cosmet Investig Dent 2012;4:9-16.

3. Batalocco G, Lee $H$, Ercoli $C$, Feng $C$, Malmstrom $\mathrm{H}$. Fracture resistance of composite resin restorations and porcelain veneers in relation to residual tooth structure in fractured incisors. Dent Traumatol 2012;28:75-80.

4. Wakiaga J, Brunton P, Silikas N, Glenny AM. Direct versus indirect veneer restorations for intrinsic dental stains. The Cochrane database of systematic reviews. 2004(1):CD004347.

5. Gresnigt MM, Ozcan M. Fracture strength of direct versus indirect laminates with and without fiber application at the cementation interface. Dent Mater 2007;23:927-33.

6. Hussain SK, McDonald A, Moles DR. In vitro study investigating the mass of tooth structure removed following endodontic and restorative procedures. J Prosthet Dent 2007;98:260-9.

7. Schmidt KK, Chiayabutr Y, Phillips KM, Kois JC. Influence of preparation design and existing condition of tooth structure on load to failure of ceramic laminate veneers. J Prosthet Dent 2011;105:374-82.

8. Friedman MJ. A 15-year review of porcelain veneer failure--a clinician's observations. Compend Contin Educ Dent 1998;19:625-8.
9. Edelhoff D, Sorensen JA. Tooth structure removal associated with various preparation designs for anterior teeth. J Prosthet Dent 2002;87:503-9.

10. Atsu SS, Aka PS, Kucukesmen HC, Kilicarslan MA, Atakan C. Age-related changes in tooth enamel as measured by electron microscopy: implications for porcelain laminate veneers. J Prosthet Dent 2005;94:336-41.

11. Christensen GJ. Has tooth structure been replaced? J Am Dent Assoc 2002;133:103-5.

12. Peumans $M$, Van Meerbeek $B$, Lambrechts $P$, Vanherle G. Porcelain veneers: a review of the literature. J Dent 2000;28:163-77.

13. Burke FJ, Lucarotti PS. Ten-year outcome of porcelain laminate veneers placed within the general dental services in England and Wales. J Dent 2009;37:31-8.

14. Hekimoglu C, Anil N, Etikan I. Effect of accelerated aging on the color stability of cemented laminate veneers. Int J Prosthodont 2000;13:29-33.

15. Stappert CF, Ozden U, Gerds T, Strub JR. Longevity and failure load of ceramic veneers with different preparation designs after exposure to masticatory simulation. J Prosthet Dent 2005;94:132-9.

16. Walls AW, Steele JG, Wassell RW. Crowns and other extra-coronal restorations: porcelain laminate veneers. Br Dent J 2002;193:73-6.

17. Burke FJ. Survival rates for porcelain laminate veneers with special reference to the effect of preparation in dentin: a literature review. J Esthet Restor Dent 2012;24:257-65.

18. Fons-Font A, Sola-Ruiz MF, Granell-Ruiz M, LabaigRueda C, Martinez-Gonzalez A. Choice of ceramic for use in treatments with porcelain laminate veneers. Med Oral Patol Oral Cir Bucal 2006;11:E297-302.

19. Dumfahrt $H$, Schaffer $H$. Porcelain laminate veneers. A retrospective evaluation after 1 to 10 years of service: Part II--Clinical results. Int J Prosthodont 2000;13:9-18.

20. Radz GM. Minimum thickness anterior porcelain restorations. Dent Clin North Am 2011;55:353-70.

21. Strassler HE. Minimally invasive porcelain veneers: indications for a conservative esthetic dentistry treatment modality. Gen Dent 2007;55:686-94.

22. Beier US, Kapferer I, Burtscher D, Dumfahrt $H$. Clinical performance of porcelain laminate veneers

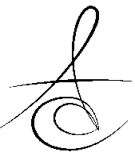


for up to 20 years. Int J Prosthodont 2012;25:7985.

23. D'Arcangelo C, De Angelis F, Vadini M, D'Amario M. Clinical evaluation on porcelain laminate veneers bonded with light-cured composite: results up to 7 years. Clin Oral Investig 2012;16:1071-9.

24. Della Bona A, Kelly JR. The clinical success of allceramic restorations. J Am Dent Assoc 2008;139:8S-13S.

25. McLaren EA, Whiteman YY. Ceramics: rationale for material selection. Compend Contin Educ Dent 2010;31:666-8.

26. McLaren EA, LeSage B. Feldspathic veneers: what are their indications? Compend Contin Educ Dent 2011;32:44-9.

27. Alghazzawi TF, Lemons J, Liu PR, Essig ME, Janowski GM. The failure load of CAD/CAM generated zirconia and glass-ceramic laminate veneers with different preparation designs. J Prosthet Dent 2012;108:386-93.

28. Chen S, Wei YJ, Chen MM, Zhang ZT. Bilateral treatment: a strategy for enhancing the mechanical strength of machinable veneers. Dent Mater 2010;26:961-7.

29. Layton D, Walton T. An up to 16-year prospective study of 304 porcelain veneers. Int J Prosthodont 2007;20:389-96.

30. Giordano R, McLaren EA. Ceramics overview: classification by microstructure and processing methods. Compend Contin Educ Dent 2010;31:682-4.

31. Peumans $M$, De Munck J, Fieuws $S$, Lambrechts $P$, Vanherle G, Van Meerbeek B.A prospective tenyear clinical trial of porcelain veneers. J Adhes Dent 2004;6:65-76.

32. Conrad HJ, Seong WJ, Pesun IJ. Current ceramic materials and systems with clinical recommendations: a systematic review. J Prosthet Dent 2007;98:389-404.

33. Sadowsky SJ. An overview of treatment considerations for esthetic restorations: a review of the literature. J Prosthet Dent 2006;96:433-42.

34. Kelly JR, Benetti P. Ceramic materials in dentistry: historical evolution and current practice. Aust Dent J 2011;56:84-96.

35. Alghazzawi TF, Lemons J, Liu PR, Essig ME, Janowski GM. Evaluation of the optical properties of CAD-CAM generated yttria-stabilized zirconia and glass-ceramic laminate veneers. J Prosthet Dent 2012;107:300-8.

36. Heffernan MJ, Aquilino SA, Diaz-Arnold AM, Haselton DR, Stanford CM, Vargas MA. Relative translucency of six all-ceramic systems. Part II: core and veneer materials. J Prosthet Dent 2002;88:10-5.

37. Baldissara P, Llukacej A, Ciocca L, Valandro FL, Scotti R. Translucency of zirconia copings made with different CAD/CAM systems. J Prosthet Dent 2010;104:6-12.

38. Reich S. Tooth-colored CAD/CAM monolithic restorations. Int J Comput Dent. 2015;18:131-46.

39. Zimmermann M, Mehl A, Reich S. New CAD/CAM materials and blocks for chairside procedures. Int J Comput Dent. 2013;16:173-81.

40. Cho SH, Chang WG, Lim BS, Lee YK. Effect of die spacer thickness on shear bond strength of porcelain laminate veneers. J Prosthet Dent 2006;95:201-8.

41. Lin TM, Liu PR, Ramp LC, Essig ME, Givan DA, Pan $\mathrm{YH}$. Fracture resistance and marginal discrepancy of porcelain laminate veneers influenced by preparation design and restorative material in vitro. J Dent 2012;40:202-9.

42. Bagis B, Turgut S. Optical properties of current ceramics systems for laminate veneers. J Dent 2013;41:e24-30.

43. Magne P, Douglas WH. Design optimization and evolution of bonded ceramics for the anterior dentition: a finite-element analysis. Quintessence Int 1999;30:661-72.

44. Calamia JR, Calamia CS. Porcelain laminate veneers: reasons for 25 years of success. Dent Clin North Am 2007;51:399-417.

45. Dhawan P, Prakash H, Shah N. Clinical and scanning electron microscopic assessments of porcelain and ceromer resin veneers. Indian J Dent Res 2003;14:264-78.

46. Fradeani M, Redemagni M, Corrado M. Porcelain laminate veneers: 6 - to 12 -year clinical evaluation-a retrospective study. Int J Periodontics Restorative Dent 2005;25:9-17.

47. Hahn P, Gustav M, Hellwig E. An in vitro assessment of the strength of porcelain veneers dependent on tooth preparation. J Oral Rehabil 2000;27:1024-9. 
48. Park DJ, Yang JH, Lee JB, Kim SH, Han JS. Esthetic improvement in the patient with one missing maxillary central incisor restored with porcelain laminate veneers. J Adv Prosthodont 2010;2:7780.

49. Gresnigt M, Ozcan M, Kalk W. Esthetic rehabilitation of worn anterior teeth with thin porcelain laminate veneers. J Eur Esthet Dent 2011;6:298-313.

50. Rotoli BT, Lima DA, Pini NP, Aguiar FH, Pereira GD, Paulillo LA. Porcelain veneers as an alternative for esthetic treatment: clinical report. Oper Dent 2013;38:459-66.

51. Reshad M, Cascione D, Magne P. Diagnostic mockups as an objective tool for predictable outcomes with porcelain laminate veneers in esthetically demanding patients: a clinical report. J Prosthet Dent 2008;99:333-9.

52. Magne $P$, Belser UC. Novel porcelain laminate preparation approach driven by a diagnostic mockup. J Esthet Restor Dent 2004;16:7-16.

53. Li Z, Yang Z, Zuo L, Meng Y. A three-dimensional finite element study on anterior laminate veneers with different incisal preparations. J Prosthet Dent 2014;112:325-33.

54. Vasconcelos FS, Neves AC, Silva-Concilio LR, Cunha LG, Rode Sde M. Influence of anatomic reference on the buccal contour of prosthetic crowns. Braz Oral Res 2009;23:230-5.

55. Shetty A, Kaiwar A, Shubhashini N, Ashwini P, Naveen D, Adarsha M, Shetty M, Meena N. Survival rates of porcelain laminate restoration based on different incisal preparation designs: An analysis. J Conserv Dent 2011;14:10-5.

56. Archangelo CM, Rocha EP, Anchieta RB, Martin M, Jr., Freitas AC, Jr., Ko CC, Cattaneo PM. Influence of buccal cusp reduction when using porcelain laminate veneers in premolars. A comparative study using 3-D finite element analysis. J Prosthodont Res 2011;55:221-7.

57. da Costa DC CM, de Sousa AS, Ennes JP. A metaanalysis of the most indicated preparation design for porcelain laminate veneers. J Adhes Dent 2013;15:215-20.

58. Fleming GJ, Jandu HS, Nolan L, Shaini FJ. The influence of alumina abrasion and cement lute on the strength of a porcelain laminate veneering material. J Dent 2004;32:67-74.
59. Soares CJ, Soares PV, Pereira JC, Fonseca RB. Surface treatment protocols in the cementation process of ceramic and laboratory-processed composite restorations: a literature review. J Esthet Restor Dent 2005;17:224-35.

60. Aykent F, Usumez A, Ozturk AN, Yucel MT. Effect of provisional restorations on the final bond strengths of porcelain laminate veneers. J Oral Rehabil 2005;32:46-50.

61. Iseri U, Oztoprak MO, Ozkurt Z, Kazazoglu E, Arun T. Effect of Er:YAG laser on debonding strength of laminate veneers. Eur ] Dent 2014;8:58-62.

62. Aykor A, Ozel E. Five-year clinical evaluation of 300 teeth restored with porcelain laminate veneers using total-etch and a modified self-etch adhesive system. Oper Dent 2009;34:516-23.

63. Dundar B, Guzel KG. An analysis of the shear strength of the bond between enamel and porcelain laminate veneers with different etching systems: acid and Er,Cr:YSGG laser separately and combined. Lasers Med Sci 2011;26:777-82.

64. Piemjai M, Watanabe A, Iwasaki Y, Nakabayashi N. Effect of remaining demineralised dentine on dental microleakage accessed by a dye penetration: how to inhibit microleakage? J Dent 2004;32:495-501.

65. Piemjai M, Arksornnukit M. Compressive fracture resistance of porcelain laminates bonded to enamel or dentin with four adhesive systems. J Prosthodont 2007; 16:457-64.

66. Buonocore MG. A simple method of increasing the adhesion of acrylic filling materials to enamel surfaces. J Dent Res 1955;34:849-53.

67. Chimello-Sousa DT, de Souza AE, Chinelatti MA, Pecora JD, Palma-Dibb RG, Milori Corona SA. Influence of Er:YAG laser irradiation distance on the bond strength of a restorative system to enamel. J Dent 2006;34:245-51.

68. Piemjai M, Miyasaka K, Iwasaki Y, Nakabayashi N. Comparison of microleakage of three acid-base luting cements versus one resin-bonded cement for Class V direct composite inlays. J Prosthet Dent 2002;88:598-603.

69. Perdigao J, Carmo AR, Anauate-Netto C, Amore R, Lewgoy $H R$, Cordeiro $H J$, et al. Clinical performance of a self-etching adhesive at 18 months. Am J Dent 2005;18:135-40. 
70. Radovic I, Monticelli F, Goracci C, Vulicevic ZR, Ferrari M. Self-adhesive resin cements: a literature review. J Adhes Dent 2008;10:251-8.

71. Lee BS, Hsieh TT, Lee YL, Lan WH, Hsu YJ, Wen $\mathrm{PH}$, et al. Bond strengths of orthodontic bracket after acid-etched, Er:YAG laser-irradiated and combined treatment on enamel surface. Angle Orthod 2003;73:565-70.

72. Van Meerbeek B, De Munck J, Yoshida Y, Inoue S, Vargas $M$, Vijay $P$, et al. Buonocore memorial lecture. Adhesion to enamel and dentin: current status and future challenges. Oper Dent 2003;28:215-35.

73. Paul SJ, Welter DA, Ghazi M, Pashley D. Nanoleakage at the dentin adhesive interface vs microtensile bond strength. Oper Dent 1999;24:181-8.

74. Koliniotou-Koumpia E, Dionysopoulos P, Koumpia E. In vivo evaluation of microleakage from composites with new dentine adhesives. J Oral Rehabil 2004;31:1014-22.

75. Leinfelder KF, Kurdziolek SM. Self-etching bonding agents. Compend Contin Educ Dent 2003;24:44754.

76. Alavi AA, Kianimanesh N. Microleakage of direct and indirect composite restorations with three dentin bonding agents. Oper Dent 2002;27:19-24.

77. Pradelle-Plasse N, Nechad S, Tavernier B, Colon P. Effect of dentin adhesives on the enameldentin/composite interfacial microleakage. Am J Dent $2001 ; 14: 344-8$.

78. Santini A, Ivanovic V, Ibbetson R, Milia $E$. Influence of cavity configuration on microleakage around Class V restorations bonded with seven self-etching adhesives. J Esthet Restor Dent 2004;16:128-35.

79. Higashi C, Dall'Agnol AL, Hirata R, Loguercio AD, Reis A. Association of enamel microabrasion and bleaching: a case report. Gen Dent 2008;56:244-9.

80. Yildiz G, Celik EU. A minimally invasive technique for the management of severely fluorosed teeth: $A$ two-year follow-up. Eur J Dent 2013;7:504-8.

81. Sundfeld RH, Croll TP, Briso AL, de Alexandre RS, Sundfeld Neto D. Considerations about enamel microabrasion after 18 years. Am J Dent 2007;20:67-72.

82. Pontes DG, Correa KM, Cohen-Carneiro F. Reestablishing esthetics of fluorosis-stained teeth using enamel microabrasion and dental bleaching techniques. J Esthet Restor Dent 2012;7:130-7.

83. Martinez-Insua A, Da Silva Dominguez L, Rivera FG, Santana-Penin UA. Differences in bonding to acid-etched or Er:YAG-laser-treated enamel and dentin surfaces. J Prosthet Dent 2000;84:280-8.

84. Usumez S, Orhan M, Usumez A. Laser etching of enamel for direct bonding with an Er,Cr:YSGG hydrokinetic laser system. Am J Orthod Dentofacial Orthop 2002;122:649-56.

85. Addison O, Marquis PM, Fleming GJ. The impact of modifying alumina air abrasion parameters on the fracture strength of a porcelain laminate restorative material. Dent Mater 2007;23:1332-41.

86. Addison O, Marquis PM, Fleming GJ. The impact of hydrofluoric acid surface treatments on the performance of a porcelain laminate restorative material. Dent Mater 2007;23:461-8.

87. Moraes RR, Correr-Sobrinho L, Sinhoreti MA, Puppin-Rontani RM, Ogliari FA, Piva E. Lightactivation of resin cement through ceramic: relationship between irradiance intensity and bond strength to dentin. J Biomed Mater Res B Appl Biomater 2008;85:160-5.

88. da Cunha LF, Pedroche LO, Gonzaga CC, Furuse AY. Esthetic, occlusal, and periodontal rehabilitation of anterior teeth with minimum thickness porcelain laminate veneers. J Prosthet Dent 2014;112:1315-8.

89. Runnacles P, Correr GM, Baratto Filho F, Gonzaga CC, Furuse AY. Degree of conversion of a resin cement light-cured through ceramic veneers of different thicknesses and types. Braz Dent J 2014;25:38-42.

90. Kilinc E, Antonson SA, Hardigan PC, Kesercioglu A. Resin cement color stability and its influence on the final shade of all-ceramics. J Dent 2011;39:e30-6.

91. Prieto LT, Souza EJ, Jr., Araujo CT, Lima AF, Dias CT, Paulillo LA. Knoop hardness and effectiveness of dual-cured luting systems and flowable resin to bond leucite-reinforced ceramic to enamel. J Prosthodont 2013;22:54-8.

92. Prieto LT, Souza-Junior EJ, Araujo CT, Lima AF, Dias CT, Paulillo LA. Nanoleakage evaluation of resin luting systems to dental enamel and leucitereinforced ceramic. Microsc Res Tech 2012;75:671-6. 
93. Altintas SH, Tak O, Secilmis A, Usumez A. Effect of provisional cements on shear bond strength of porcelain laminate veneers. Eur J Dent 2011;5:373-9.

94. Dumfahrt $H$, Gobel $G$. Bonding porcelain laminate veneer provisional restorations: An experimental study. J Prosthet Dent 1999;82:281-5.

95. Ozturk E, Bolay S, Hickel R, Ilie N. Shear bond strength of porcelain laminate veneers to enamel, dentine and enamel-dentine complex bonded with different adhesive luting systems. J Dent 2013;41:97-105.

96. Ratnaweera PM, Fukagawa N, Tsubota Y, Fukushima $S$. Microtensile bond strength of porcelain laminate veneers bonded to fluorosed teeth. J Prosthodont 2009;18:205-10.

97. Ghavam M, Amani-Tehran M, Saffarpour M. Effect of accelerated aging on the color and opacity of resin cements. Oper Dent 2010;35:605-9.

98. Turgut S, Bagis B. Colour stability of laminate veneers: an in vitro study. J Dent 2011;39:e57-64.

99. Turgut S, Bagis B. Effect of resin cement and ceramic thickness on final color of laminate veneers: an in vitro study. J Prosthet Dent 2013;109:179-86.

100. Chen JH, Shi CX, Wang M, Zhao SJ, Wang H. Clinical evaluation of 546 tetracycline-stained teeth treated with porcelain laminate veneers. J Dent 2005;33:3-8.

101.Grannel-Ruiz M, Fons-Font A, Labaig-Rueda C, Martinez-Gonzalez A, Roman-Rodruigez JL, SolaRuiz FM. A clinical longitudinal study 323 porcelain laminate veneers. Period of study from 3 to 11 years. Med Oral Patol Cir Buccal 2010;15:531-7.

102. Meijering AC, Creugers NH, Mulder J, Roeters FJ. Treatment times for three different types of veneer restorations. J Dent1995;23:21-6.

103.Gresnigt MM, Kalk W, Ozcan M. Randomized clinical trial of indirect resin composite and ceramic veneers: up to 3-year follow-up. J Adhes Dent 2013;15:181-90.

104. Farhan D, Sukumar S, von Stein-Lausnitz A, Aarabi G, Alawneh A, Reissmann DR. Masking ability of bi- and tri- laminate all-ceramic veneers on tooth-colored ceramic discs. J Esthet Restor Dent 2014;26:232-9.
105.Granell-Ruiz M, Agustin-Panadero R, Fons-Font A, Roman-Rodriguez $\mathrm{JL}$, Sola-Ruiz MF. Influence of bruxism on survival of porcelain laminate veneers. Med Oral Patol Oral Cir Bucal 2014;19:e426-32.

106. Murphy E, Ziada HM, Allen PF. Retrospective study on the performance of porcelain laminate veneers delivered by undergraduate dental students. Eur J Prosthodont Restor Dent 2005;13:38-43.

107. Köroğlu A, Ekren O, Kurtoğlu C. Geleneksel ve adeziv dental simanlar hakkinda bir derleme çalişmasi. J Dent Fac Atatürk Uni 2012;22:205-16.

108. Guess PC, Stappert CF. Midterm results of a 5year prospective clinical investigation of extended ceramic veneers. Dent Mater 2008;24:804-13.

109. Cotert HS, Dundar M, Ozturk B. The effect of various preparation designs on the survival of porcelain laminate veneers. J Adhes Dent 2009;11:405-11.

110. Alhekeir DF, Al-Sarhan RA, Al Mashaan AF. Porcelain laminate veneers: Clinical survey for evaluation of failure. Saudi Dent J 2014;26:63-7.

\author{
Yazışma Adresi \\ Dt. Hamit Fatih Erkün \\ Gazi Üniversitesi, Diş Hekimliği Fakültesi, \\ Protetik Diş Tedavisi Anabilim Dalı \\ Emek 8.cad Ankara \\ Tel: 0312204196 \\ e-mail: dt.fatiherkun@hotmail.com
}

